\title{
JUURNAL_RU
}

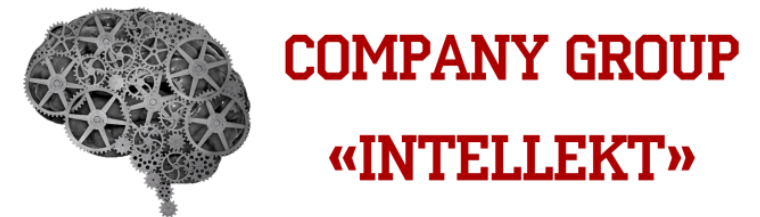

Рудаков О.М. Вятский государственный университет

Киров, Россия

doi: 10.18411/lj2016-3-31

\section{Клавиатурный почерк как метод биометрической аутентификации}

Одна из достаточно сложных задач, повседневно решаемых многими людьми, - быстрый набор текстов с клавиатуры компьютера. Обычно быстрого клавиатурного ввода информации удается достичь за счет использования всех пальцев обеих рук. При этом у каждого человека проявляется свой уникальный клавиатурный почерк. Клавиатурный почерк - это набор динамических характеристик работы на клавиатуре.

Современные исследования показывают, что клавиатурный почерк пользователя обладает стабильностью, что позволяет достаточно однозначно идентифицировать пользователя, работающего с клавиатурой.

В качестве исходных данных используют временные интервалы между нажатием клавиш на клавиатуре и время их удержания. При этом временные интервалы между нажатием клавиш характеризуют темп работы, а время удержания клавиш характеризует стиль работы с клавиатурой - резкий удар или плавное нажатие.

Идентификация пользователя по клавиатурному почерку возможна следующими способами:

- по набору ключевой фразы;

- по набору произвольного текста.

Оба способа подразумевают два режима работы: обучение и 
идентификация. На этапе обучения пользователь вводит один или несколько раз предлагаемые ему тестовые фразы. При этом рассчитываются и запоминаются эталонные характеристики данного пользователя. На этапе идентификации рассчитанные оценки сравниваются с эталонными, на основании чего делается вывод о совпадении или несовпадении параметров клавиатурного почерка.

Выбор текста, на котором выполняется обучение системы, - достаточно важный этап для нормального функционирования системы. Предлагаемые пользователю фразы необходимо подбирать таким образом, чтобы используемые в них символы полностью и равномерно покрывали рабочее поле клавиатуры.

Возможна организация "неявного" процесса обучения системы, когда программа перехватывает весь ввод с клавиатуры и соответственно рассчитывает эталонные характеристики пользователя. Данная процедура достаточно легко организуется практически в любой операционной системе.

Однако существует ряд ограничений по применению данного способа на практике. Применение способа идентификации по клавиатурному почерку целесообразно только по отношению к пользователям с достаточно длительным опытом работы с компьютером и сформировавшимся почерком работы на клавиатуре. В противном случае вероятность неправильного опознания "легального" пользователя существенно возрастает и делает непригодным данный способ идентификации на практике.

Эталонные характеристики пользователя, полученные на этапе обучения системы, позволяют сделать выводы о степени стабильности клавиатурного почерка пользователя и определить доверительный интервал разброса параметров для последующей идентификации пользователя.

В задаче идентификации пользователя по клавиатурному почерку важным этапом является обработка первичных данных. В результате этой обработки входной поток данных разделяется на ряд признаков, характеризующих те или иные качества идентифицируемой личности. В 
дальнейшем эти признаки, подвергаясь статистической обработке, позволяют получить ряд эталонных характеристик пользователя.

Формирование эталонов пользователей - это процесс сбора информации о пользователях на основе их наборных характеристик, которые включают в себя определённые параметры клавиатурного почерка. В дальнейшем эти эталоны записывают в память системы распознавания.

Одной из первых задач с которой сталкиваются в процессе формирования эталонов - это выбор параметров клавиатурного почерка. Существует несколько важных требований предъявляемых к выбранным параметрам: устойчивость значений параметров и их индивидуальность, то есть параметры почерка должны быть различны у различных пользователей.

Отсюда вытекает ещё одна необходимость - сведение к минимуму объём а эталонов пользователей для уменьшения памяти базы эталонов. При таком подходе появляется возможность упрощения системы распознавания клавиатурного почерка, а соответственно и разработки быстрых алгоритмов распознавания, что позволяет свести к минимуму затраты машинного времени.

Преимущества использования клавиатурного почерка для аутентификации:

- Простота реализации и внедрения. Реализация исключительно программная, ввод осуществляется со стандартного устройства ввода (клавиатуры), а значит, использование не требуется приобретение никакого дополнительного оборудования. Это самый дешевый способ аутентификации по биометрическим характеристикам субъекта доступа.

- Не требует от пользователя никаких дополнительных действий, кроме привычных. Пользователь так или иначе, наверняка, использует пароль, который можно назначить парольной фразой, по которой будет проводиться аутентификация. 
- Возможность скрытой аутентификации - пользователь даже может быть не в курсе, что включена дополнительная проверка, а значит не сможет об этом сообщить злоумышленнику.

Данный метод изучался в работах отечественных и зарубежных ученых, но многие вопросы еще не исследованы до конца. Так максимальная полученная точность аутентификации составляет на данный момент 95\% (Леггетт, Умфресс, Уильямс, 1989). [2] Однако для аутентификации по их методу требуется зафиксировать нажатия порядка 5000 клавиш, что неприемлемо для практического использования.

Такой же достоверности удалось добиться Шарипову Р.Р., но он для этого использовал специальные клавиатуры с датчиком, фиксирующим скорость движения клавиши при ее нажатии.[3]

Следовательно, актуальна разработка новых методов, алгоритмов и их реализаций, повышающих надежность систем аутентификации по клавиатурному почерку.

\section{Литература:}

1. Казарин М.Н. Разработка и исследование методов скрытного клавиатурного мониторинга: автореф. дис. канд. техн. наук; 05.13.19. /Таганрог, 2006.- 181 с.

2. G. Leggett, J. Williams and D. Umphress. Verification of User Identity via Keystroke Characteristics. Human Factors in Management Information Systems, 1989.

3. Шарипов Р.Р. Разработка полигауссового алгоритма аутентификации пользователей в телекоммуникационных системах и сетях по клавиатурному почерку: автореферат диссертации на соискание ученой степени канд. техн. наук: 05.12.13 / Р.Р. Шарипов. - Казань, 2006. - 16 с. 